\title{
Treatment of Nonalcoholic Fatty Liver Disease (NAFLD) in patients with Type 2 Diabetes Mellitus
}

\author{
Paola Portillo-Sanchez ${ }^{1}$ and Kenneth Cusi ${ }^{1,2^{*}}$
}

\begin{abstract}
Nonalcoholic fatty liver disease (NAFLD) is believed to be the most common chronic liver disease, affecting at least one-third of the population worldwide. The more aggressive form is known as nonalcoholic steatohepatitis (NASH) and characterized by hepatocyte necrosis and inflammation. The presence of fibrosis is not uncommon. Fibrosis indicates a more aggressive course and patients with NASH that are at high-risk of cirrhosis and premature mortality, as well as at increased risk of hepatocellular carcinoma (HCC). Patients with type 2 diabetes mellitus (T2DM) are at the highest risk for the development of NASH, even in the setting of normal plasma aminotransferase levels. The presence of dysfunctional adipose tissue in most overweight and obese subjects, combined with insulin resistance, hyperglycemia, and atherogenic dyslipidemia, contribute to their increased cardiovascular risk. Many therapeutic agents have been tested for the treatment of NASH but few studies have focused in patients with T2DM. At the present moment, the only FDA-approved agents that in controlled studies have shown to significantly improve liver histology in patients with diabetes are pioglitazone and liraglutide. Current research efforts are centering on the mechanisms for intrahepatic triglyceride accumulation and for the development of steatohepatitis, the role of mitochondrial dysfunction in NASH, and the impact of improving glycemic control per se on the natural history of the disease. This brief review summarizes our current knowledge on the pharmacological agents available for the treatment of NASH to assist healthcare providers in the management of these challenging patients.
\end{abstract}

Keywords: Nonalcoholic fatty liver disease (NAFLD), Nonalcoholic steatohepatitis (NASH), Type 2 diabetes mellitus, Insulin resistance, Metformin, Thiazolinediones, Pioglitazone, Dipeptidyl peptidase 4 (DPP-4) inhibitors, Glucagon-like peptide-1 receptor agonists (GLP-1RA), Sodium-glucose co-transporter 2 (SGLT2) inhibitors

\section{Background}

Nonalcoholic fatty liver disease (NAFLD) is the most common liver disease in the United States [1], affecting about $60-70 \%$ of all obese individuals. With one-third of adults being obese, and a similar proportion being overweight, a large number of Americans are at risk of developing the disease [2]. The future magnitude of the problem can be better appreciated knowing that more than one-third of the pediatric population is overweight or obese [3]. Nonalcoholic fatty liver disease encompasses a broad spectrum of disease severity, ranging

\footnotetext{
* Correspondence: Kenneth.Cusi@medicine.ufl.edu

'Division of Endocrinology, Diabetes and Metabolism, University of Florida, 1600 SW Archer Road, room H-2, Gainesville, FL 32610, USA

${ }^{2}$ Division of Endocrinology, Diabetes, and Metabolism, Malcom Randall Veterans Affairs Medical Center, Gainesville, FL 32608, USA
}

from isolated steatosis to its more severe form with variable degrees of hepatocyte inflammation, necrosis and liver fibrosis, known as nonalcoholic steatohepatitis (NASH) [4, 5]. Of note, among the histologic features of $\mathrm{NASH}$, fibrosis is the more strongly correlated with endstage liver disease and increased mortality [6, 7]. The presence of obesity and insulin resistance, often with clinical features of the metabolic syndrome (but not necessarily), leads to a high-risk profile for the development of NAFLD. However, it is the presence of T2DM that confers the highest risk for NAFLD, and specially, for NASH. The highest mortality in NAFLD/NASH arises not from end-stage liver disease, or an increased risk of hepatocellular carcinoma ( $\mathrm{HCC})$, but secondary to cardiovascular disease $[8,9]$. This may be explained by worse atherogenic risk factors such as hyperglycemia, 
hyperinsulinemia [10] and dyslipidemia [11], among others.

Unfortunately, in the clinical setting, the lack of a reliable non-invasive diagnostic blood test or imaging technique for its diagnosis has let to underestimate the true prevalence of this condition. The prevalence of NAFLD in the general population is $34 \%$ measured by the goldstandard technique of magnetic resonance and spectroscopy $\left({ }^{1} \mathrm{H}-\mathrm{MRS}\right)$, but about 2 -fold higher in obese patients [12]. In a recent study in obese patients with T2DM and normal liver aminotransferases, the prevalence of NAFLD was $56 \%$ and more than half of those undergoing a liver biopsy had NASH [13]. A populationwide liver biopsy study examining the prevalence of $\mathrm{NASH}$ in T2DM is not available given the invasive nature of the procedure. However, in a recent study in 3041 patients from the Rotterdam Study, a populationbased study among individuals $\geq 45$ years of age, Koehler et al. [14] reported that one out of six patients with T2DM had a diagnosis of fibrosis using a combined non-invasive screening approach of liver ultrasound and liver transient elastography. Taken together, it has become evident that NASH is a significant risk factor for future severe liver and cardiovascular disease. There is a need for increased awareness among clinicians to diagnose and treat early-on these patients.

\section{Role of dysfunctional adipose tissue and lipotoxicity}

The pathophysiology of NAFLD is complex and multifactorial $[1,15,16]$. In the context of obesity and T2DM (both highly prevalent in NAFLD), mitochondrial dysfunction, insulin resistance and adipose tissue inflammation play a major role. It is well established that white adipose tissue is an active endocrine organ with potential to have major metabolic effects [17]. Adipose tissue secretes a diversity of adipokines that can have a pro- or anti-inflammatory effects $[18,19]$. Obesity is commonly linked with adipose tissue activation of macrophages that promote a proinflammatory state and a state of subclinical inflammation that is also typical in patients with NAFLD. The presence of dysfunctional adipose tissue leads to increased rates of lipolysis and flux of free fatty acids to ectopic tissues activating apoptotic pathways and/or generating subsequent insulin resistance in muscle and liver [20]. The development of a "lipotoxic state" in NASH is central to activation of inflammatory pathways that lead to hepatocyte necroinflammation, and potentially a major target for therapy, as will be discussed in the next section.

\section{Therapeutic interventions}

\section{Diet and lifestyle modification}

Many studies have been done in NAFLD involving lifestyle modification and/or weight loss by dietary modification only. Most studies report a reduction in plasma aminotransferases and often improvement in hepatic steatosis. However, the data is often from small, poorly controlled studies and have rarely focused on patients with T2DM. Also, most have used surrogate endpoints to assess liver improvement, such as plasma aminotransferases or liver ultrasound, and rarely liver histology [21, 22]. A number of recent studies quantifying hepatic steatosis by ${ }^{1} \mathrm{H}-\mathrm{MRS}$ indicate that a modest weight reduction in the range of 5$10 \%$ with exercise alone, or combined with caloric restriction, significantly reduces intrahepatic triglycerides (IHTG) by about $40 \%$ [20]. In general, reduction in IHTG content (and improvement in cardiovascular risk factors) is proportional to the magnitude of weight loss induced by lifestyle intervention, as well demonstrated in a substudy of the Look Ahead that quantified hepatic triglycerides by ${ }^{1} \mathrm{H}$-MRS [23]. For instance, patients losing 5 to $10 \%$ of weight had a $65 \%$ decrease in IHTG, while the few achieving a $\geq 10 \%$ lost $80 \%$. Similar results were reported by Wong et al. [24] after lifestyle intervention in a 12month RCT in 154 patients with NAFLD, where a significant $5.6 \mathrm{~kg}$ total body weight reduction was associated with a $55 \%$ decrease in IHTG (liver triglyceride content changing from 12.3 to $5.5 \%$ ). Unfortunately, the impact on liver histology was not examined in either study, but Promrat et al. [25] did report that a reduction of total body weight of $\geq 9 \%$ is associated with a broad histological improvement in steatosis, necrosis and inflammation in patients with NASH. Patients with NASH undergoing bariatric surgery also have in most cases a reduction of hepatic steatosis, hepatocyte necrosis and inflammation, with less certain effects on fibrosis [26, 27]. However, improvement in fibrosis by weight loss or lifestyle changes is less well established and no specific dietary plan (other than caloric restriction) appears to be uniquely beneficial in NASH. The weight loss agents phentermine/topiramate, lorcaserin and naltrexone/bupropion have not undergone careful testing in a RCT in patients with $\mathrm{NASH}$, but they may likely assist in improving histology as they may decrease body weight by $\sim 10 \%$ at maximal doses. In any case, improvement in dietary habits and increased physical activity leading to weight loss are fundamental interventions for the treatment of both T2DM and NAFLD.

\section{Pharmacological agents}

Many agents have been tested for the treatment of NASH but most not specifically in patients with T2DM. For instance, agents that modify cholesterol metabolism such as statins or ezetemibe have been extensively studied $[28,29]$. Statins can be safely given to patients with NAFLD/NASH to reduce their increased cardiovascular risk [30]. Several small studies have suggested some 
benefit of statins in NAFLD/NASH, although usually they have been short-term, uncontrolled trials using surrogate primary end points (such as plasma aminotransferases or imaging) rather than liver histology. No histological improvement was reported when comparing statin therapy versus placebo in the only 12 -month controlled study using liver histology as the primary endpoint [31]. Taken together, there is consensus that statins do not improve hepatocyte ballooning or fibrosis in NASH, but are safe to prevent cardiovascular disease in this population. Ezetimibe may decrease IHTG, but its efficacy to improve steatohepatitis is unknown [32].

Omega-3 polyunsaturated fatty acids (PUFAs) activate peroxisome proliferator-activated receptor (PPAR) $\alpha$ receptors, which upregulate several genes involved in fatty acid oxidation, holding potential to reduce hepatic steatosis and downregulate pro-inflammatory pathways in NAFLD/NASH. While small, uncontrolled studies have reported a reduction in plasma aminotransferases and liver steatosis, recent studies with omega- 3 fatty acids have been negative [33-36]. In summary, there appears to be no major role for PUFAs for the treatment of NASH.

Vitamin $\mathrm{E}$ is an anti-oxidant believed to reduce hepatocyte oxidative stress in patients with NASH [1]. In non-diabetic patients with biopsy-proven NASH vitamin E led to significant histological improvement in the primary endpoint (improvement in $\geq 2$ grades in the NAFLD activity score [NAS], including hepatocellular ballooning and with no worsening of fibrosis), compared to placebo $(p=0.001)$ [37]. However, resolution of NASH did not reach statistical significance (36 \% vs. $21 \%, p=0.05)$, an endpoint only reached in the same study by pioglitazone ( $47 \%, p=0.001$ vs. placebo). Vitamin $\mathrm{E}$ also did not significantly improve histology in a large RCT in a pediatric population with NASH, although some histological features did improve (i.e., hepatocellular ballooning) [38]. In summary, vitamin E may be beneficial in patients with NASH without T2DM because it is relatively inexpensive and at the dose used (800 IU per day) it appears to be safe $[39,40]$. However, its long-term efficacy has not been established in NASH and it has not been tested in patients with T2DM.

Pentoxifylline is a non-selective phosphodiesterase inhibitor that may decrease inflammatory pathways in NASH, such as TNF- $\alpha$ [28]. Several open-label, small studies reported mixed results on plasma aminotransferases and hepatic steatosis on imaging [41]. Two small 12-month studies have reported on histology. While in one study in 30 patients with NASH pentoxifylline did not improve histology compared to placebo [42], another small trial ( $n=20$ patients) reported some improvement in steatosis, lobular inflammation and fibrosis after 1 year [43]. More work is clearly needed to define its role in NAFLD and in patients with T2DM, a population never studied with this agent.

\section{Metformin}

Metformin is considered first-line therapy for the management in T2DM given its ability to improve insulin action and lower plasma glucose without hypoglycemia, as well as its potential for weight loss [44]. Given that patients with NAFLD/NASH have insulin resistance, it has been extensively tested in this setting. Early studies suggested histological benefit, but this was likely more related to concomitant weight loss in uncontrolled studies than to the biguanide per se $[45,46]$ (Table 1). For instance, in the study by Loomba et al. [45], the correlation of histological improvement with weight loss was very high $(r=0.79, p<$ $0.0001)$, and improvement in the NAFLD activity score happened largely in patients that lost $\geq 5 \%$ of body weight (i.e., in four out of five patients). More recently, similar negative results were also reported in a RCT in 173 children (mean age: 13 years) assigned to either metformin $1000 \mathrm{mg}$, vitamin E $800 \mathrm{U}$ or placebo for 96 months [38]. Several recent meta-analysis have included bettercontrolled studies and have concluded that metformin is

Table 1 Therapeutic agents for T2DM and their effect NAFLD/NASH in clinical trials

\begin{tabular}{|c|c|c|c|c|}
\hline Treatment & Mechanism of action & AST/ALT & Liver fat by imaging & Liver histology \\
\hline \multicolumn{5}{|l|}{ Oral } \\
\hline Metformin [38,45-48] & Insulin-sensitizer & $\downarrow$ & $\downarrow^{*}, \leftrightarrow \wedge$ & Unchanged \\
\hline Pioglitazone $[52,53,55]$ & PPARy agonist & $\downarrow$ & $\downarrow^{\wedge}$ & Improved \\
\hline Sitagliptin $[72,80,81]$ & DPP-4 inhibitor & $\downarrow$ & $\mathrm{n} / \mathrm{a}$ & $\mathrm{n} / \mathrm{a}$ \\
\hline Vildagliptin [82] & DPP-4 inhibitor & $\downarrow$ & $\downarrow^{\wedge}$ & $\mathrm{n} / \mathrm{a}$ \\
\hline Canagliflozin [90] & Inhibits renal glucose reabsortion & $\downarrow$ & $\mathrm{n} / \mathrm{a}$ & $\mathrm{n} / \mathrm{a}$ \\
\hline Dapagliflozin $[91,92]$ & Inhibits renal glucose reabsortion & $\downarrow$ & $\mathrm{n} / \mathrm{a}$ & $\mathrm{n} / \mathrm{a}$ \\
\hline \multicolumn{5}{|l|}{ Injectable } \\
\hline Exenatide [70] & GLP-1 receptor agonist & $\downarrow$ & $\downarrow^{\wedge}$ & $\mathrm{n} / \mathrm{a}$ \\
\hline Liraglutide [69-75] & GLP-1 receptor agonist & $\downarrow$ & $\downarrow^{* * \wedge} \wedge$ & Improved \\
\hline
\end{tabular}

*NAFLD assessed by ultrasound, **NAFLD assessed by CT, ^NAFLD assessed by MRI/1 H-MRS, n/a: data not available 
not effective for the treatment of NASH $[47,48]$. However, it must be highlighted that all glucose-lowering drugs approved for the treatment of type 2 diabetes are safe in NAFLD/NASH, unless advanced cirrhosis. Metformin is not liver-metabolized but largely eliminated by renal clearance, and can can be used safely in the vast majority of patients with NASH.

\section{Thiazolinediones: role of pioglitazone}

Thiazolinediones (TZDs) are ligands for the transcription factor PPAR- $\gamma$ that plays a key role in the regulation of glucose and lipid metabolism, as well as in inflammation [49]. PPAR- $\gamma$ is predominately expressed in adipose tissue, but is also present in many other tissues that regulate metabolic pathways such as the pancreas, liver and muscle. At least part of the mechanism of action of TZDs relates to restoring normal adipose tissue biology. Treatment with TZDs is associated with an amelioration of proinflammatory adipokines and an increase in the secretion of adiponectin by adipocytes [50], restoring the response of adipose tissue to insulin action, as well as at the level of the liver and skeletal tissue [20]. Evidence for the long-term impact of these broad metabolic and antiinflammatory effects can be appreciated in the potential for pioglitazone to prevent the progression to T2DM in patients with impaired glucose tolerance, improving not only plasma glucose levels but also blood pressure and lipid levels [51], all factors that play an important role in the morbidity and mortality of patients with T2DM.

Both pioglitazone and rosiglitazone have been tested in patients with NASH [47]. Early studies were small, uncontrolled and reported mixed clinical results [20,47] Belfort et al. [52], in a proof-of-concept 6-month trial in patients with prediabetes and T2DM, reported the first RCT of pioglitazone (plus a $-500 \mathrm{kcal} /$ day caloric restricted diet) in patients with biopsy-proven NASH. Patients had a significant improvement in hepatic steatosis, and necroinflammation. The NAFLD activity score (NAS) improved in $73 \%$ of patients treated with pioglitazone compared to only $24 \%$ in the placebo group with diet alone $(p<0.001)$. There was also a suggestion that fibrosis could be reversed in NASH, as pioglitazonetreated patients had a significant reduction in liver fibrosis compared to baseline, although this fell short of reaching statistical significance when compared to placebo $(p=0.08)$. This study was important in establishing that the histological abnormalities present in NASH could potentially be halted, and even reversed, within a relatively short period of time. Two additional RCTs later extended these findings to patients with NASH but without diabetes $[37,53]$, but rosiglitazone proved to be rather ineffective [54]. Recently, Cusi et al. [55] reported a 36-month study in 101 patients with prediabetes or T2DM and NASH. They found sustained histological and metabolic benefit with long-term treatment. Of note, there was also a modest but statistically significant difference in the mean scores for fibrosis when compared to placebo. The fact that improvement persisted over time suggests that pioglitazone may modify the natural history of the disease [56]. Treatment was well tolerated, with only mild weight gain $(2.5 \mathrm{~kg}$ versus placebo). Potential side effects associated with TZDs include weight gain from either improved insulin action in adipocytes with increased triglyceride synthesis and overall adiposity, or rarely, from fluid retention. Development of shortness of breath or congestive heart failure is rare $(\sim 1 \%$ or less) in the setting of pioglitazone treatment, and is related to unknown diastolic dysfunction that is common in T2DM. Finally, mild bone loss may occurr in women [49]. Recently, Lewis et al. [57] demonstrated in a long-term prospective study lack of an association between pioglitazone and bladder cancer. Of note, TZDs treatment has been associated with a reduction in a broad spectrum of cancers $[58,59]$ and with a decrease in cardiovascular mortality [60].

\section{Glucagon-like peptide-1 (GLP-1) receptor agonists}

GLP-1 receptor agonists (GLP-1RA) may become an attractive therapeutic option for the treatment of patients with T2DM and NASH given their broad spectrum of effects on glucose and lipid metabolism. Their structure prevents them from being immediately cleaved and inactivated by circulating dipeptidyl peptidase (DPP)- 4 prolonging their systemic actions. Glucose-lowering by GLP-1RA is attributed to enhancement of insulin secretion, reduction of postprandial glucagon concentration, effects at the level of the central nervous system with appetite suppression and induction of weight loss, as well as improvement of insulin action in hepatocytes and adipose tissue [61]. It has been proposed that there may be direct binding to hepatic GLP-1 receptors that may account for at least part of the beneficial metabolic action in the liver [62-64]. A number of animal studies have shown that GLP-1 analogs improve hepatic insulin sensitivity and decrease steatosis [62, 64-66], and even fibrosis [67]. Exendin-4 significantly reduces hepatic de novo lipogenesis (DNL) in vitro and in vivo [68]. This is important as increased DNL is believed to play a significant role in NAFLD.

Several studies hinted at a potential benefit of GLP-1RA, but evidence until recently was inconclusive. A significant decrease in plasma aminotransferase levels and hepatic steatosis (assessed by CT scan) was observed at the higher dose of liraglutide $(1.8 \mathrm{mg})$ in a meta-analysis of $6 \mathrm{RCT}$ LEAD (Liraglutide Efficacy and Action in Diabetes) trials [69]. However, this difference was not significant after adjustment for weight $(p=0.25)$ or A1c $(p=0.93)$, suggesting an effect primarly associated with these factors. In an early 
study, Cuthberson et al. [70] found that 6 months of GLP1RA therapy (19 with exenatide and 6 with liraglutide) was associated with significant weight loss of $5.0 \mathrm{~kg}$, a $1.6 \%$ A1c reduction and a $42 \%$ relative reduction in IHTG (all $p<0.001)$. The relative reduction in IHTG correlated with A1c $(r=0.49 ; p=0.01)$, but not significantly with change in total body weight, visceral or subcutaneous adipose tissue. Similar findings have been reported in other small uncontrolled studies [71, 72]. Eguchi et al. [73] also reported a reduction in body mass index (BMI), visceral fat accumulation, aminotransferases and hyperglycemia in 19 patients with biopsy-proven NASH treated with liraglutide for 24 weeks, with histological improvement in 6 out of 10 who had a repeat liver biopsy after 96 weeks of liraglutide treatment. Finally, in a recent uncontrolled study while both insulin glargine and liraglutide similarly decreased A1c levels, only insulin significanty decreased IHTG from baseline [74]. However, the study was hampered by the small sample size $(n=35)$ and significant number of dropouts ( $20 \%)$, short duration of follow-up (3 months) and the low-dose of liraglutide used ( $1.3 \mathrm{mg} /$ day).

In the most comprehensive study to date, the LEAN (Liraglutide Efficacy and Action in Non-alcoholic steatohepatitis) trial showed benefit when 52 patients with biopsy-proven NASH were treated for 48 weeks with liraglutide at a dose of $1.8 \mathrm{mg}$ per day [75]. Only one-third of the population had T2DM, but overall patients were obese and had evidence of insulin resistance. After treatment, $39 \%$ of patients that received liraglutide had resolution of $\mathrm{NASH}$ (defined as disappearance of hepatocyte ballooning without worsening of fibrosis) compared to only $9 \%$ in the placebo arm. While fibrosis did not improve with liraglutide, more patients in the placebo arm experienced worsening of fibrosis $(p=0.04)$. Patients treated with liraglutide had a significant reduction of body weight, fasting plasma glucose and A1c levels. A subset of patients accepted to undergo in-depth glucose and lipid turnover studies before and after 12 weeks of liraglutide treatment. This resulted in improved insulin sensitivity at the level of the liver, as well as a decrease in hepatic DNL. Insulin action in adipose tissue also improved, both fasting and in response to low-dose insulin infusion (i.e., suppression of systemic and with directly measured subcutaneaous microdialysis techniques). However, the improvements in insulin sensitivity were overall modest, and confounded by weight loss. Moreover, enhanced adipose tissue insulin sensitivity was not observed (i.e., Adipo-IR $R_{\text {index }}$ ) when the entire cohort was analyzed [75].

Taken together, treatment of patients with T2DM and NAFLD with GLP-1RA is an approach that calls for larger, long-term studies, to fully understand their therapeutic potential and the role of mechanisms that account for their efficacy beyond weight reduction or amelioration of hyperglycemia.

\section{Dipeptidyl peptidase-4 (DPP-4) inhibitors}

An alternate therapetic option for the treatment of NAFLD in T2DM are DPP-4 inhibitors. Their mechanism of action is primarily from the blockade of the multifunctional protein DPP-4 that degrades glucagonlike peptide-1 (GLP-1) and plays a key role in postprandial glucose homeostasis [76, 77]. These pharmacolgical agents primarily lower the postprandial plasma glucose $(\sim 50 \mathrm{mg} / \mathrm{dl})$ and reduce A1c levels by $\sim 0.6$ to $0.8 \%$ [78]. Also animal studies have shown their ability to reduce liver triglyceride content and inflammation [79].

The role of these agents in NAFLD has been tested in short-term clinical trials. Reduction in plasma aminotransferases have been reported with sitagliptin in Japanese patients with T2DM and NAFLD [72, 80]. In contrast, in another study plasma aminotransferases did not improve in patients with biopsy-proven NAFLD treated with sitagliptin for 12 months [81]. In a 6-month RCT in 44 patients with T2DM, Macauley et al. [82] reported that vildagliptin $50 \mathrm{mg}$ twice daily significantly decreased plasma alanine aminotransferase (ALT) levels (from 27 to $20 \mathrm{IU} / \mathrm{L}, p<0.001$ ) and IHTG by ${ }^{1} \mathrm{H}$-MRS (from $7.3 \%$ to $5.3 \%, p=0.001)$. Of note, plasma ALT was not truly elevated at baseline. Moreover, IHTG were only mildy increased before treatment (normal considered to be $\leq 5.5 \%$ ). However, a robust correlation was found between a decrease in the plasma aminotransferases and the triglyceride liver content $(r=0.83 ; p<0.0001)$, confirming the close correlation between liver triglyceride content and plasma ALT [83]. In this study, there was no improvement in liver, muscle or adipose tissue insulin sensitivity. Reduction in IHTG did not correlate with changes in body weight but rather with the decrease in fasting plasma glucose at 3 months $(r=0.47$; $p=0.02)$ and 6 months $(r=0.44 ; p=0.03)$.

It should be noted that overall, the effect of DPP-4 inhibitors appears to be modest, although large RCTs with histological endpoints are lacking to conclusively establish their role in patients with T2DM and NASH.

\section{Sodium-glucose co-transporter 2 (SGLT2) inhibitors}

These agents inhibit the reabsorption of glucose in the proximal tubular system with a marked reduction of plasma glucose levels $[84,85]$. At the present moment three agents are approved: dapagliflozin, canagliflozin and empagliflozin. Their use is also associated with a reduction of total body weight, possibly as a secondary effect of caloric loss and increased diuresis [86]. Recently, empagliflozin has been associated with a reduction in cardiovascular mortality [87].

Studies performed in rodents have shown that SGLT2 inhibitors, in addition to the reduction of plasma glucose concentration, decrease hepatic triglyceride accumulation and other inflammatory biomarkers $[88,89]$. While 
these agents are now well-established therapeutic agents for the treatment of T2DM, their specific impact in NAFLD remains to be determined. The administration of canagliflozin (100 or $300 \mathrm{mg}$ per day) for 52 weeks is associated with a reduction in plasma liver aminotransferases, especially at the higher dose, but their impact on liver histology is unknown [90]. While a small study did not see such en effect with dapagliflozin [91], Bailey et al. [92] reported a reduction in plasma ALT concentration in a larger 24-week trial. Considering that these pharmacologic agents ameliorate hyperglycemia, induce weight loss, and may improve insulin sensitivity, they are actively being explored for the treatment of NAFLD/ NASH in patients with T2DM.

\section{Future treatments}

Awareness about the high prevalence and significant health risks associated with NASH in patients with T2DM has led in recent times to a major drug discovery effort in this field. As a result, a variety of clinical trials are being conducted for the treatment of NASH, as reviewed elsewhere $[93,94]$. For instance, the FLINT study found benefit with the treatment of obeticholic acid, a farnesoid X receptor (FXR), compared to placebo [95]. Recently, results from the GOLDEN 505 trail, a PPAR $\alpha / \delta$ agonist, believed to combine the benefits on lipid metabolism of a PPAR $\alpha$ and the effects on insulin sensitivity of PPAR $\delta$ agonist, failed to meet the primary endpoint of resolution of NASH but reported some histological benefit in patients with a higher NAS score $(\geq 4)[96]$.

\section{Conclusions}

The presence of NASH is common among patients with T2DM, putting them at risk of end-stage liver disease, HCC and cardiovascular disease. Physicians must increase their awareness about the high-risk of complications associated with NAFLD/NASH and the emerging broad spectrum of therapeutic options. Lifestyle modification is essential. While a Mediterranean diet has been advocated to be beneficial, well-designed controlled studies are needed [97] and the best diet for the longterm management of NAFLD remains uncertain. Caloric restriction with weight loss $\geq 10 \%$ appears to be essential for histological response. The addition of pharmacologic agents early-on, especially pioglitazone, has the potential to improve the quality of life and prevent severe comorbidities in this population.

\footnotetext{
Abbreviations

${ }^{1} \mathrm{H}-\mathrm{MRS}$ : proton magnetic resonance spectroscopy; A1C: hemoglobin A1C; Adipo-IR: adipose tissue insulin resistance; ALT: alanine aminotransferase; BMl: body mass index; CT: computed tomography; CVD: cardiovascular disease; DNL: de novo lipogenesis; DPP-4: dipeptidyl peptidase-4; GLP1RA: glucagon like peptide-1 receptor agonist; HCC: hepatocellular carcinoma; IHTG: intrahepatic triglycerides; NAFLD: nonalcoholic fatty liver disease; NAS: NAFLD activity score; NASH: nonalcoholic steatohepatitis;
}

PPAR: peroxisome proliferator-activated receptor; PUFAs: polyunsaturated fatty acids; RCT: randomized controlled trials; SGLT2: sodium-glucose cotransporter 2; T2DM: type 2 diabetes mellitus; TZDs: thiazolinediones.

\section{Competing interests}

Kenneth Cusi $(\mathrm{KC})$ has received research grant support from Janssen Pharmaceutical Co. of Johnson \& Johnson and Novartis Pharmaceuticals. He is a consultant for Janssen Pharmaceutical Co. of Johnson \& Johnson, Eli Lilly and Company and Tobira Therapeutics, Inc. Paola Portillo-Sanchez (PPS) has no competing interests.

\section{Authors' contributions}

PPS and KC have participated in the writing and editing of this manuscript. Both authors read and approved the final manuscript.

Received: 2 February 2016 Accepted: 28 March 2016

Published online: 12 April 2016

References

1. Rinella ME. Nonalcoholic fatty liver disease: a systematic review. JAMA. 2015; 313:2263-73.

2. Yang $L$, Colditz GA. Prevalence of overweight and obesity in the United States, 2007-2012. JAMA Intern Med. 2015;175:1412-3.

3. Ogden CL, Carroll MD, Kit BK, Flegal KM. Prevalence of childhood and adult obesity in the United States, 2011-2012. JAMA. 2014;311:806-14

4. Brunt EM, Kleiner DE, Wilson LA, Belt P, Neuschwander-Tetri BA, Network NCR. Nonalcoholic fatty liver disease (NAFLD) activity score and the histopathologic diagnosis in NAFLD: distinct clinicopathologic meanings. Hepatology. 2011:53:810-20.

5. Hjelkrem M, Stauch C, Shaw J, Harrison SA. Validation of the non-alcoholic fatty liver disease activity score. Aliment Pharmacol Ther. 2011;34:214-8.

6. Angulo $P$, Kleiner DE, Dam-Larsen S, Adams LA, Bjornsson ES, Charatcharoenwitthaya P, Mills PR, Keach JC, Lafferty HD, Stahler A, Haflidadottir S, Bendtsen F. Liver Fibrosis, but no other histologic features, is associated with long-term outcomes of patients with nonalcoholic fatty liver disease. Gastroenterology. 2015;149:389-97.

7. Ekstedt M, Hagstrom H, Nasr P, Fredrikson M, Stal P, Kechagias S, Hultcrantz R. Fibrosis stage is the strongest predictor for disease-specific mortality in NAFLD after up to 33 years of follow-up. Hepatology. 2015;61:1547-54.

8. Luo J, Xu L, Li J, Zhao S. Nonalcoholic fatty liver disease as a potential risk factor of cardiovascular disease. Eur J Gastroenterol Hepatol. 2015;27:193-9.

9. Lonardo A, Sookoian S, Pirola CJ, Targher G. Non-alcoholic fatty liver disease and risk of cardiovascular disease. Metabolism. 2015. doi:10.1016/j.metabol. 2015.09.017

10. Bril F, Lomonaco R, Orsak B, Ortiz-Lopez C, Webb A, Tio F, Hecht J, Cusi K. Relationship between disease severity, hyperinsulinemia, and impaired insulin clearance in patients with nonalcoholic steatohepatitis. Hepatology. 2014;59:2178-87.

11. Bril F, Sninsky JJ, Baca AM, Robert Superko H, Portillo Sanchez P, Biernacki D, Maximos M, Lomonaco R, Orsak B, Suman A, Weber MH, McPhaul MJ, Cusi K. Hepatic steatosis and insulin resistance, but not steatohepatitis, promote atherogenic dyslipidemia in NAFLD. J Clin Endocrinol Metab. 2016;101:644-52.

12. Browning JD, Szczepaniak LS, Dobbins R, Nuremberg P, Horton JD, Cohen JC, Grundy SM, Hobbs HH. Prevalence of hepatic steatosis in an urban population in the United States: impact of ethnicity. Hepatology. 2004;40:1387-95.

13. Portillo-Sanchez P, Bril F, Maximos M, Lomonaco R, Biernacki D, Orsak B, Subbarayan S, Webb A, Hecht J, Cusi K. High prevalence of nonalcoholic fatty liver disease in patients with type 2 diabetes mellitus and normal plasma aminotransferase levels. J Clin Endocrinol Metab. 2015;100:2231-8.

14. Koehler EM, Plompen EP, Schouten JN, Hansen BE, Darwish Murad S, Taimr P, Leebeek FW, Hofman A, Stricker BH, Castera L, Janssen HL. Presence of diabetes mellitus and steatosis is associated with liver stiffness in a general population: The Rotterdam study. Hepatology. 2016;63:138-47.

15. Neuschwander-Tetri BA. NASH: the tribulations of conducting NASH trials. Nat Rev Gastroenterol Hepatol. 2014;11:274-6.

16. Szendroedi J, Phielix E, Roden M. The role of mitochondria in insulin resistance and type 2 diabetes mellitus. Nat Rev Endocrinol. 2012;8:92-103.

17. Stern JH, Scherer PE. Adipose tissue biology in 2014: Advances in our understanding of adipose tissue homeostasis. Nat Rev Endocrinol. 2015;11:71-2. 
18. Rodriguez A, Ezquerro S, Mendez-Gimenez L, Becerril S, Fruhbeck G. Revisiting the adipocyte: a model for integration of cytokine signaling in the regulation of energy metabolism. Am J Physiol Endocrinol Metab. 2015; 309:E691-714.

19. Ziemke F, Mantzoros CS. Adiponectin in insulin resistance: lessons from translational research. Am J Clin Nutr. 2010;91:258S-61.

20. Cusi K. Role of obesity and lipotoxicity in the development of nonalcoholic steatohepatitis: pathophysiology and clinical implications. Gastroenterology. 2012;142:711-25

21. Marchesini G, Petta S, Dale Grave R. Diet, weight loss, and liver health in NAFLD: pathophysiology, evidence and practice. Hepatology 2015; Dec 11. doi: 10.1002/hep.28392.

22. Thoma C, Day CP, Trenell MI. Lifestyle interventions for the treatment of non-alcoholic fatty liver disease in adults: a systematic review. J Hepatol. 2012:56:255-66.

23. Lazo M, Solga SF, Horska A, Bonekamp S, Diehl AM, Brancati FL, Wagenknecht LE, Pi-Sunyer FX, Kahn SE, Clark JM. Effect of a 12-month intensive lifestyle intervention on hepatic steatosis in adults with type 2 diabetes. Diabetes Care. 2010;33:2156-63.

24. Wong W, Chan RS, Wong GL, Cheung BH, Chu WC, Yeung DK, Chim AM, Lai JW, Li LS, Sea MM, Chan FK, Sung JJ, Woo J, Chan HL. Community-based lifestyle modification programme for non-alcoholic fatty liver disease: a randomized controlled trial. J Hepatol. 2013;59:536-42.

25. Promrat K, Kleiner DE, Niemeier HM, Jackvony E, Kearns M, Wands JR, Fava JL, Wing RR. Randomized controlled trial testing the effects of weight loss on nonalcoholic steatohepatitis. Hepatology. 2010;51:121-9.

26. Moretto M, Kupski C, da Silva VD, Padoin AV, Mottin CC. Effect of bariatric surgery on liver fibrosis. Obes Surg. 2012;22:1044-9.

27. de Almeida SR, Rocha PR, Sanches MD, Leite VH, da Silva RA, Diniz MT, Diniz Mde F, Rocha AL. Roux-en Y gastric bypass improves the nonalcoholic steatohepatitis (NASH) of morbid obesity. Obes Surg. 2006;16:270-8.

28. Lomonaco R, Sunny NE, Bril F, Cusi K. Nonalcoholic fatty liver disease: current issues and novel treatment approaches. Drugs. 2013;73:1-14.

29. Bril F, Lomonaco R, Cusi K. The challenge of managing dyslipidemia in patients with nonalcoholic fatty liver disease. Clin Lipidol. 2012;7:471-81.

30. Chalasani N, Younossi Z, Lavine JE, Diehl AM, Brunt EM, Cusi K, Charlton M, Sanyal AJ, American Gastroenterological A, American Association for the Study of Liver D, American College of G. The diagnosis and management of non-alcoholic fatty liver disease: practice guideline by the American Gastroenterological Association, American Association for the Study of Liver Diseases, and American College of Gastroenterology. Gastroenterology. 2012;142:1592-609.

31. Nelson A, Torres DM, Morgan AE, Fincke C, Harrison SA. A pilot study using simvastatin in the treatment of nonalcoholic steatohepatitis: A randomized placebo-controlled trial. J Clin Gastroenterol. 2009;43:990-4.

32. Chan DC, Watts GF, Gan SK, Ooi EM, Barrett PH. Effect of ezetimibe on hepatic fat, inflammatory markers, and apolipoprotein B-100 kinetics in insulin-resistant obese subjects on a weight loss diet. Diabetes Care. 2010;33:1134-9.

33. Dasarathy S, Dasarathy J, Khiyami A, Yerian L, Hawkins C, Sargent R, McCullough AJ. Double-blind randomized placebo-controlled clinical trial of omega 3 fatty acids for the treatment of diabetic patients with nonalcoholic steatohepatitis. J Clin Gastroenterol. 2015:49:137-44.

34. Scorletti E, Bhatia L, McCormick KG, Clough GF, Nash K, Hodson L, Moyses HE, Calder PC, Byrne CD, Study W. Effects of purified eicosapentaenoic and docosahexaenoic acids in nonalcoholic fatty liver disease: results from the WELCOME study. Hepatology. 2014;60:1211-21.

35. Sanyal AJ, Abdelmalek MF, Suzuki A, Cummings OW, Chojkier M, Group E-AS. No significant effects of ethyl-eicosapentanoic acid on histologic features of nonalcoholic steatohepatitis in a phase 2 trial. Gastroenterology. 2014;147:377-84.

36. Parker HM, Johnson NA, Burdon CA, Cohn JS, O'Connor HT, George J. Omega-3 supplementation and non-alcoholic fatty liver disease: a systematic review and meta-analysis. J Hepatol. 2012;56:944-51.

37. Sanyal AJ, Chalasani N, Kowdley KV, McCullough A, Diehl AM, Bass NM, Neuschwander-Tetri BA, Lavine JE, Tonascia J, Unalp A, Van Natta M, Clark J, Brunt EM, Kleiner DE, Hoofnagle JH, Robuck PR, NASH CRN. Pioglitazone, vitamin $\mathrm{E}$, or placebo for nonalcoholic steatohepatitis. N Engl J Med. 2010; 362:1675-85.

38. Lavine JE, Schwimmer JB, Van Natta ML, Molleston JP, Murray KF, Rosenthal P, Abrams SH, Scheimann AO, Sanyal AJ, Chalasani N, Tonascia J, Unalp A, Clark JM,
Brunt EM, Kleiner DE, Hoofnagle JH, Robuck PR, Nonalcoholic Steatohepatitis Clinical Research Network. Effect of vitamin E or metformin for treatment of nonalcoholic fatty liver disease in children and adolescents: the TONIC randomized controlled trial. JAMA. 2011;305:1659-68.

39. Klein EA, Thompson Jr IM, Tangen CM, Crowley JJ, Lucia MS, Goodman PJ, Minasian LM, Ford LG, Parnes HL, Gaziano JM, Karp DD, Lieber MM, Walther PJ, Klotz L, Parsons JK, Chin JL, Darke AK, Lippman SM, Goodman GE, Meyskens FL, Jr., Baker LH. Vitamin $\mathrm{E}$ and the risk of prostate cancer: the selenium and vitamin $\mathrm{E}$ cancer prevention trial (SELECT). JAMA. 2011;306:1549-56.

40. Miller ER 3rd, Pastor-Barriuso R, Dalal D, Riemersma RA, Appel LJ, Guallar E. Meta-analysis: high-dosage vitamin $\mathrm{E}$ supplementation may increase allcause mortality. Ann Intern Med. 2005;142:37-46.

41. Li W, Zheng L, Sheng C, Cheng X, Qing L, Qu S. Systematic review on the treatment of pentoxifylline in patients with non-alcoholic fatty liver disease. Lipids Health Dis. 2011;10:49.

42. Van Wagner LB, Koppe SW, Brunt EM, Gottstein J, Gardikiotes K, Green RM, Rinella ME. Pentoxifylline for the treatment of non-alcoholic steatohepatitis: a randomized controlled trial. Ann Hepatol. 2011;10:277-86.

43. Zein CO, Yerian LM, Gogate P, Lopez R, Kirwan JP, Feldstein AE, McCullough AJ. Pentoxifylline improves nonalcoholic steatohepatitis: a randomized placebocontrolled trial. Hepatology. 2011:54:1610-9.

44. Inzucchi SE, Bergenstal RM, Buse JB, Diamant M, Ferrannini E, Nauck M, Peters AL, Tsapas A, Wender R, Matthews DR. Management of hyperglycaemia in type 2 diabetes, 2015: a patient-centred approach. Update to a position statement of the American Diabetes Association and the European Association for the Study of Diabetes. Diabetologia. 2015;58:429-42.

45. Loomba R, Lutchman G, Kleiner DE, Ricks M, Feld JJ, Borg BB, Modi A, Nagabhyru P, Sumner AE, Liang TJ, Hoofnagle JH. Clinical trial: pilot study of metformin for the treatment of non-alcoholic steatohepatitis. Aliment Pharmacol Ther. 2009;29:172-82.

46. Bugianesi E, Gentilcore E, Manini R, Natale S, Vanni E, Villanova N, David E, Rizzetto M, Marchesini G. A randomized controlled trial of metformin versus vitamin E or prescriptive diet in nonalcoholic fatty liver disease. Am J Gastroenterol. 2005;100:1082-90.

47. Musso G, Gambino R, Cassader M, Pagano G. A meta-analysis of randomized trials for the treatment of nonalcoholic fatty liver disease. Hepatology. 2010;52:79-104.

48. Ratziu V, Caldwell S, Neuschwander-Tetri BA. Therapeutic trials in nonalcoholic steatohepatitis: insulin sensitizers and related methodological issues. Hepatology. 2010;52:2206-15.

49. Yau H, Rivera K, Lomonaco R, Cusi K. The future of thiazolidinedione therapy in the management of type 2 diabetes mellitus. Curr Diab Rep. 2013:13:329-41.

50. Soccio RE, Chen ER, Lazar MA. Thiazolidinediones and the promise of insulin sensitization in type 2 diabetes. Cell Metab. 2014;20:573-91.

51. DeFronzo RA, Tripathy D, Schwenke DC, Banerji M, Bray GA, Buchanan TA, Clement SC, Henry RR, Hodis HN, Kitabchi AE, Mack WJ, Mudaliar S, Ratner RE, Williams K, Stentz FB, Musi N, Reaven PD, Study AN. Pioglitazone for diabetes prevention in impaired glucose tolerance. $\mathrm{N}$ Engl J Med. 2011;364:1104-15.

52. Belfort R, Harrison SA, Brown K, Darland C, Finch J, Hardies J, Balas B, Gastaldelli A, Tio F, Pulcini J, Berria R, Ma JZ, Dwivedi S, Havranek R, Fincke C, DeFronzo R, Bannayan GA, Schenker S, Cusi K. A placebo-controlled trial of pioglitazone in subjects with nonalcoholic steatohepatitis. N Engl J Med. 2006;355:2297-307.

53. Aithal GP, Thomas JA, Kaye PV, Lawson A, Ryder SD, Spendlove I, Austin AS, Freeman JG, Morgan L, Webber J. Randomized, placebo-controlled trial of pioglitazone in nondiabetic subjects with nonalcoholic steatohepatitis. Gastroenterology. 2008;135:1176-84.

54. Ratziu V, Giral P, Jacqueminet S, Charlotte F, Hartemann-Heurtier A, Serfaty L, Podevin P, Lacorte JM, Bernhardt C, Bruckert E, Grimaldi A, Poynard T, Group LS. Rosiglitazone for nonalcoholic steatohepatitis: one-year results of the randomized placebo-controlled Fatty Liver Improvement with Rosiglitazone Therapy (FLIRT) trial. Gastroenterology. 2008;135:100-10.

55. Cusi K, Orsak B, Lomonaco R, Bril F, Ortiz-Lopez C, Hecht J, et al. Extended treatment with pioglitazone improves liver histology in patients with prediabetes or type 2 diabetes mellitus and NASH. Hepatology. 2013;58:Abstract \#82.

56. Portillo P, Yavuz S, Bril F, Cusi K. Role of insulin resistance and diabetes in the patogenesis and treatment of nonalcoholic fatty liver disease. Curr Hepatology Rep. 2014;13:159-70. 
57. Lewis JD, Habel LA, Quesenberry CP, Strom BL, Peng T, Hedderson MM, Ehrlich SF, Mamtani R, Bilker W, Vaughn DJ, Nessel L, Van Den Eeden SK, Ferrara A. Pioglitazone use and risk of bladder cancer and other common cancers in persons with diabetes. JAMA. 2015;314:265-77.

58. Chang CH, Lin JW, Wu LC, Lai MS, Chuang LM, Chan KA. Association of thiazolidinediones with liver cancer and colorectal cancer in type 2 diabetes mellitus. Hepatology. 2012;55:1462-72.

59. Monami M, Dicembrini I, Mannucci E. Thiazolidinediones and cancer: results of a meta-analysis of randomized clinical trials. Acta Diabetol. 2014;51:91-101.

60. Lincoff AM, Wolski K, Nicholls SJ, Nissen SE. Pioglitazone and risk of cardiovascular events in patients with type 2 diabetes mellitus: a metaanalysis of randomized trials. JAMA. 2007;298:1180-8.

61. Campbell JE, Drucker DJ. Pharmacology, physiology, and mechanisms of incretin hormone action. Cell Metab. 2013;17:819-37.

62. Ding X, Saxena NK, Lin S, Gupta NA, Anania FA. Exendin-4, a glucagon-like protein-1 (GLP-1) receptor agonist, reverses hepatic steatosis in ob/ob mice. Hepatology. 2006;43:173-81.

63. Gupta NA, Mells J, Dunham RM, Grakoui A, Handy J, Saxena NK, Anania FA. Glucagon-like peptide-1 receptor is present on human hepatocytes and has a direct role in decreasing hepatic steatosis in vitro by modulating elements of the insulin signaling pathway. Hepatology. 2010;51:1584-92.

64. Svegliati-Baroni G, Saccomanno S, Rychlicki C, Agostinelli L, De Minicis S, Candelaresi C, Faraci G, Pacetti D, Vivarelli M, Nicolini D, Garelli P, Casini A, Manco M, Mingrone G, Risaliti A, Frega GN, Benedetti A, Gastaldelli A. Glucagon-like peptide-1 receptor activation stimulates hepatic lipid oxidation and restores hepatic signalling alteration induced by a high-fat diet in nonalcoholic steatohepatitis. Liver Int. 2011;31:1285-97.

65. Ben-Shlomo S, Zvibel I, Shnell M, Shlomai A, Chepurko E, Halpern Z, Barzilai N, Oren R, Fishman S. Glucagon-like peptide-1 reduces hepatic lipogenesis via activation of AMP-activated protein kinase. J Hepatol. 2011;54:1214-23.

66. Lee J, Hong SW, Chae SW, Kim DH, Choi JH, Bae JC, Park SE, Rhee EJ, Park CY, Oh KW, Park SW, Kim SW, Lee WY. Exendin-4 improves steatohepatitis by increasing sirt1 expression in high-fat diet-induced obese C57BL/6 J mice. PLoS One. 2012;7:e31394.

67. Trevaskis JL, Griffin PS, Wittmer C, Neuschwander-Tetri BA, Brunt EM, Dolman CS, Erickson MR, Napora J, Parkes DG, Roth JD. Glucagon-like peptide-1 receptor agonism improves metabolic, biochemical, and histopathological indices of nonalcoholic steatohepatitis in mice. Am J Physiol Gastrointest Liver Physiol. 2012;302:G762-72.

68. Armstrong MJ, Hull D, Guo K, Barton D, Hazlehurst JM, Gathercole LL, Nasiri M, Yu J, Gough SC, Newsome PN, Tomlinson JW. Glucagon-like peptide 1 decreases lipotoxicity in non-alcoholic steatophepatitis. J Hepatol. 2016;64:399-408.

69. Armstrong MJ, Houlihan DD, Rowe IA, Clausen WH, Elbrond B, Gough SC, Tomlinson JW, Newsome PN. Safety and efficacy of liraglutide in patients with type 2 diabetes and elevated liver enzymes: individual patient data metaanalysis of the LEAD program. Aliment Pharmacol Ther. 2013;37:234-42.

70. Cuthbertson DJ, Irwin A, Gardner CJ, Daousi C, Purewal T, Furlong N, Goenka N, Thomas EL, Adams VL, Pushpakom SP, Pirmohamed M, Kemp GJ. Improved glycaemia correlates with liver fat reduction in obese, type 2 diabetes, patients given glucagon-like peptide-1 (GLP-1) receptor agonists. PLoS One. 2012;7:e50117.

71. Jendle J, Nauck MA, Matthews DR, Frid A, Hermansen K, During M, Zdravkovic M, Strauss BJ, Garber AJ, LEAD-2 and LEAD-3 study groups. Weight loss with liraglutide, a once-daily human glucagon-like peptide1 analogue for type 2 diabetes treatment as monotherapy or added to metformin, is primarily as a result of a reduction in fat tissue. Diabetes Obes Metab. 2009;11:1163-72.

72. Ohki T, Isogawa A, Iwamoto M, Ohsugi M, Yoshida H, Toda N, Tagawa K, Omata M, Koike $\mathrm{K}$. The effectiveness of liraglutide in nonalcoholic fatty liver disease patients with type 2 diabetes mellitus compared to sitagliptin and pioglitazone. Sci World J. 2012;2012:496453.

73. Eguchi Y, Kitajima Y, Hyogo H, Takahashi H, Kojima M, Ono M, Araki N, Tanaka K, Yamaguchi M, Matsuda Y, Ide Y, Otsuka T, Ozaki I, Ono N, Eguchi T, Anzai K, Japan Study Group for N. Pilot study of liraglutide effects in non-alcoholic steatohepatitis and non-alcoholic fatty liver disease with glucose intolerance in Japanese patients (LEAN-J). Hepatol Res. 2015;45:269-78.

74. Tang A, Rabasa-Lhoret R, Castel H, Wartelle-Bladou C, Gilbert G, MassicotteTisluck K, Chartrand G, Olivie D, Julien AS, de Guise J, Soulez G, Chiasson JL. Effects of insulin glargine and liraglutide therapy on liver fat as measured by magnetic resonance in patients with type 2 diabetes: a randomized trial. Diabetes Care. 2015;38:1339-46.
75. Armstrong MJ, Gaunt P, Aithal GP, Barton D, Hull D, Parker R, Hazlehurst JM, Guo K, team Lt, Abouda G, Aldersley MA, Stocken D, Gough SC, Tomlinson JW, Brown RM, Hubscher SG, Newsome PN. Liraglutide safety and efficacy in patients with non-alcoholic steatohepatitis (LEAN): a multicentre, double-blind, randomised, placebo-controlled phase 2 study. Lancet. 2016;387:679-90.

76. Mulvihill EE, Drucker DJ. Pharmacology, physiology, and mechanisms of action of dipeptidyl peptidase-4 inhibitors. Endocr Rev. 2014;35:992-1019.

77. Zarrinpar A, Loomba R. Review article: the emerging interplay among the gastrointestinal tract, bile acids and incretins in the pathogenesis of diabetes and non-alcoholic fatty liver disease. Aliment Pharmacol Ther. 2012;36:909-21.

78. Dicker D. DPP-4 inhibitors: impact on glycemic control and cardiovascular risk factors. Diabetes Care. 2011;34 Suppl 2:S276-8.

79. Shirakawa J, Fujii H, Ohnuma K, Sato K, Ito Y, Kaji M, Sakamoto E, Koganei M, Sasaki H, Nagashima Y, Amo K, Aoki K, Morimoto C, Takeda E, Terauchi Y. Diet-induced adipose tissue inflammation and liver steatosis are prevented by DPP-4 inhibition in diabetic mice. Diabetes. 2011;60:1246-57.

80. Iwasaki T, Yoneda M, Inamori M, Shirakawa J, Higurashi T, Maeda S, Terauchi Y, Nakajima A. Sitagliptin as a novel treatment agent for nonalcoholic fatty liver disease patients with type 2 diabetes mellitus. Hepatogastroenterology. 2011;58:2103-5.

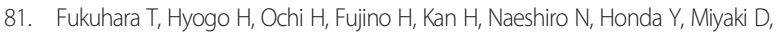
Kawaoka T, Tsuge M, Hiramatsu A, Imamura M, Kawakami Y, Aikata H, Chayama K. Efficacy and safety of sitagliptin for the treatment of nonalcoholic fatty liver disease with type 2 diabetes mellitus. Hepatogastroenterology. 2014;61:323-8.

82. Macauley M, Hollingsworth KG, Smith FE, Thelwall PE, Al-Mrabeh A, Schweizer A, Foley JE, Taylor R. Effect of vildagliptin on hepatic steatosis. J Clin Endocrinol Metab. 2015;100:1578-85.

83. Maximos M, Bril F, Portillo Sanchez P, Lomonaco R, Orsak B, Biernacki D, Suman A, Weber M, Cusi K. The role of liver fat and insulin resistance as determinants of plasma aminotransferase elevation in nonalcoholic fatty liver disease. Hepatology. 2015;61:153-60.

84. Haas B, Eckstein N, Pfeifer V, Mayer P, Hass MD. Efficacy, safety and regulatory status of SGLT2 inhibitors: focus on canagliflozin. Nutr Diabetes. 2014;4:e143.

85. Stenlof K, Cefalu WT, Kim KA, Alba M, Usiskin K, Tong C, Canovatchel W, Meininger G. Efficacy and safety of canagliflozin monotherapy in subjects with type 2 diabetes mellitus inadequately controlled with diet and exercise. Diabetes Obes Metab. 2013;15:372-82.

86. Mudaliar S, Polidori D, Zambrowicz B, Henry RR. Sodium-glucose cotransporter inhibitors: effects on renal and intestinal glucose transport: from bench to bedside. Diabetes Care. 2015;38:2344-53.

87. Zinman B, Wanner C, Lachin JM, Fitchett D, Bluhmki E, Hantel S, Mattheus M, Devins T, Johansen OE, Woerle HJ, Broedl UC, Inzucchi SE, EMPA-REG OUTCOME Investigators. Empagliflozin, cardiovascular outcomes, and mortality in type 2 diabetes. N Engl J Med. 2015;373:2117-28.

88. Hayashizaki-Someya Y, Kurosaki E, Takasu T, Mitori H, Yamazaki S, Koide K, Takakura S. Ipragliflozin, an SGLT2 inhibitor, exhibits a prophylactic effect on hepatic steatosis and fibrosis induced by choline-deficient l-amino aciddefined diet in rats. Eur J Pharmacol. 2015;754:19-24.

89. Yokono M, Takasu T, Hayashizaki Y, Mitsuoka K, Kihara R, Muramatsu Y, Miyoshi S, Tahara A, Kurosaki E, Li Q, Tomiyama H, Sasamata M, Shibasaki M, Uchiyama Y. SGLT2 selective inhibitor ipragliflozin reduces body fat mass by increasing fatty acid oxidation in high-fat diet-induced obese rats. Eur J Pharmacol. 2014;727:66-74.

90. Lavalle-Gonzalez FJ, Januszewicz A, Davidson J, Tong C, Qiu R, Canovatchel W, Meininger G. Efficacy and safety of canagliflozin compared with placebo and sitagliptin in patients with type 2 diabetes on background metformin monotherapy: a randomised trial. Diabetologia. 2013;56:2582-92.

91. List JF, Woo V, Morales E, Tang W, Fiedorek FT. Sodium-glucose cotransport inhibition with dapagliflozin in type 2 diabetes. Diabetes Care. 2009:32:650-7.

92. Bailey CJ, Gross JL, Pieters A, Bastien A, List JF. Effect of dapagliflozin in patients with type 2 diabetes who have inadequate glycaemic control with metformin: a randomised, double-blind, placebo-controlled trial. Lancet. 2010;375:2223-33.

93. Filozof C, Goldstein BJ, Williams RN, Sanyal A. Non-alcoholic steatohepatitis: limited available treatment options but promising drugs in development and recent progress towards a regulatory approval pathway. Drugs. 2015;75:1373-92.

94. Harrison SA. NASH, from diagnosis to treatment: Where do we stand? Hepatology. 2015;62:1652-5. 
95. Neuschwander-Tetri BA, Loomba R, Sanyal AJ, Lavine JE, Van Natta ML, Abdelmalek MF, Chalasani N, Dasarathy S, Diehl AM, Hameed B, Kowdley KV McCullough A, Terrault N, Clark JM, Tonascia J, Brunt EM, Kleiner DE, Doo E, Network NCR. Farnesoid X nuclear receptor ligand obeticholic acid for noncirrhotic, non-alcoholic steatohepatitis (FLINT): a multicentre, randomised, placebo-controlled trial. Lancet. 2015;385:956-65.

96. Ratziu V, Harrison S, Francque S, Bedossa P, Lehert P, Serfaty L, et al. Elafibranor, an agonist of the peroxisome proliferator-activated receptor-a and $-\delta$, induces resolution of nonalcoholic steatohepatitis without fibrosis worsening. Gastroenterology. 2016. doi:10.1053/j.gastro.2016.01.038.

97. Abenavoli L, Milic N, Peta V, Alfieri F, De Lorenzo A, Bellentani S. Alimentary regimen in non-alcoholic fatty liver disease: Mediterranean diet. World J Gastroenterol. 2014;20:16831-40.

Submit your next manuscript to BioMed Central and we will help you at every step:

- We accept pre-submission inquiries

- Our selector tool helps you to find the most relevant journal

- We provide round the clock customer support

- Convenient online submission

- Thorough peer review

- Inclusion in PubMed and all major indexing services

- Maximum visibility for your research

Submit your manuscript at www.biomedcentral.com/submit
Biomed Central 